Pak. j. sci. ind. res. Ser. A: phys. sci. 201558 (3) 149-156

\title{
Evaluation of the Impact of Continuously Regenerating Trap on Volatile Organic Compounds Emitted from Turbocharged Diesel Engine
}

\author{
Asad Naeem Shah ${ }^{a b *}$, Ge Yun-shan ${ }^{b}$, Muhammad Mehmood Aslam Bhutta ${ }^{a}$, \\ Anees Ur Rehman ${ }^{\mathrm{a}}$, Ahmad Naveed ${ }^{\mathrm{a}}$ and Muhammad Imran Masood ${ }^{\mathrm{a}}$ \\ ${ }^{a}$ Department of Mechanical Engineering, University of Engineering and Technology, \\ Lahore-54000, Pakistan \\ ${ }^{\mathrm{b}}$ School of Mechanical and Vehicular Engineering, Beijing Institute of Technology, \\ Beijing-100081, PR China
}

(receivd January 20, 2014; revised May 30, 2014; accepted June 16, 2014)

\begin{abstract}
In this study a continuously regenerating trap (CRT) was evaluated on the basis of its performance to control the volatile organic compounds (VOCs) emitted from the diesel engine exhaust. The engine was operated on a test bench by coupling it through an AC electrical dynamometer under the auspices of an 8 -mode steady-state cycle. VOCs in their gaseous phase were trapped in Tenax $\mathrm{TA}^{\circledR}$ cartridge, and then extracted by thermal desorber (TD) for the subsequent analysis through gas chromatograph-mass spectrometer (GC/MS). According to the results, VOCs were preponderant during both maximum as well as minimum load modes owing to the incomplete combustion. Benzene and toluene were in abundance with respective maximum relative contribution (RC) of 40.3 and $34.7 \%$ in upstream of CRT, while toluene and ethyl benzene were the dominant species with respective maximum RC of 38.2 and $30.8 \%$ in downstream of CRT. Styrene and butyl acetate were the least contributors to total VOCs in both upstream as well as downstream of CRT. The CRT unit revealed a good control on VOCs with maximum reduction rate $\left(R_{R}\right)$ of $45 \%$. The $R_{R}$ of VOCs was decreased with the decrease in $\mathrm{NO}_{2} / \mathrm{NO}_{\mathrm{x}}$ ratio, while the $R_{R}$ of benzene was reduced with the reduction in downstream temperature leading to strong correlations between them. Moreover, the $R_{R}$ trend of both benzene and ethyl benzene led to an important finding that when former was substantially reduced with maximum $R_{R}$, the latter remained elevated with higher negative $R_{R}$. Hence, an anti-correlation was found between benzene and ethyl benzene.
\end{abstract}

Keywords: continuously regenerating trap, compression ignition engine, unregulated emissions, volatile organic compounds

\section{Introduction}

During the last few decades diesel engine is facing twin challenges of rapidly exhausting fossil fuel reservoirs and ever tighter emission regulations. Several environmental protection agencies are of the view that diesel exhaust adversely affects the air quality and human health, and thus consider it as a probable human carcinogen (Tang et al., 2007). Consequently, researchers of automotive field are working hard for the survival of this power train against the future emission legislations which are expected to be more stringent with the passage of time.

Current emission regulations of diesel engine address the gaseous pollutants including total hydrocarbon (THC), carbon monoxide (CO) and nitrogen oxides $\left(\mathrm{NO}_{\mathrm{x}}\right)$, as well as particulate matter $(\mathrm{PM})$ emissions on

*Author for correspondence; E-mail: naeem_138@hotmail.com the basis of quantity and strategy. These regulations/ directives emphasize on some definite rules and protocols for the collection of pollutants, and for their subsequent analysis. Therefore, all such emissions following the above directives are known as regulated emissions. Unregulated emissions, on the other hand, are also gaining the attention of researchers owing to their potential threats both to environment as well as human health. These emissions normally include polycyclic aromatic hydrocarbons (PAHs), carbonyls or aldehydes and ketones, accumulation and nuclei mode particle numbers, volatile organic compounds, etc.

VOCs being ubiquitous and numerous consist of organic chemicals and reactive compounds which are responsible for photochemical smog or ground level ozone, and thus play a definite role in the stratospheric ozone depletion (Liu et al., 2012; Tang et al., 2004). Aromatic compounds such as xylene isomers, toluene and benzene have been 
declared as suspected carcinogens, and prolonged exposure to them may cause leukemia (US EPA, 1990). According to the US National Institute for Occupational Safety and Health (NIOSH), $p, m$-xylene may disturb the human central nervous and reproduction systems, $o$-xylene may damage the central nervous and hearing systems, toluene may adversely affect the human nervous system, and thus decrease the learning ability. Moreover, benzene being a probable carcinogen to humans may disturb the blood forming organs, immune system and liver (Haupt et al., 2004).

A variety of options such as fuels, additives, engine hardware alterations and after treatment technologies are now available which may be used either separately or in suitable combinations for the abatement of exhaust emissions (Shah et al., 2012; Biswas et al., 2009). Over the past few years, after treatment units such as selective catalytic reduction (SCR), diesel oxidation catalyst (DOC), diesel particulate filter (DPF), and particle oxidation catalyst (POC) have been employed by the researchers either independently or in integrated forms to control such emissions (Liu et al., 2012; Shah et al., 2012). The emission control technologies are serving not only the criteria of regulated emissions but have also revealed their potential to alleviate the unregulated pollutants as well (Shah et al., 2012; Liu et al., 2011; Shah et al., 2011; Jiang et al., 2010).

Among the various DPF units, continuously regenerating DPF commonly known as continuously regenerating trap (CRT) has proved to be an effective and promising after treatment system to reduce both regulated emissions as well as some classes of unregulated species (Shah et al., 2012; Liu et al., 2011; Lanni et al., 2001). It consists of DOC and trap portions which serve the purpose of oxidation of $\mathrm{CO}, \mathrm{NO}$ and $\mathrm{THC}$, and the filtration or trapping of particulates, respectively (Cooper and Thoss, 1989). The gaseous $\mathrm{NO}_{2}$ produced by the oxidation of $\mathrm{NO}$ is further used to burn the trapped material in the filter under normal operating temperature of $250^{\circ} \mathrm{C}$ (Walker et al., 2003). This phenomenon of combustion of PM material collected in the filter to make it clean for the subsequent trapping is called regeneration, and thus system is called continuously regenerating trap (CRT) on account of its continuous activity of regeneration.

The efficiency of a CRT unit to collect the pollutants is dependent on two important processes known as diffusion and interception, along with two forces i.e. electrophoresis and thermophoresis (Liu et al., 2010). Higher the efficiency of a trap, larger is the accumulated mass of pollutants which require the higher restrained gas to be passed through it. This leads to the inhibition of the engine performance both in brake power and fuel economy. Moreover, higher sulphur content in a fuel may retard the regeneration process of the trap (Allansson et al., 2002).

The CRT system is basically designed and developed with an aim to abate the PM emissions as well as regulated gaseous emissions through trapping filter and oxidation catalyst, respectively. Objective of the current study is to investigate the impacts of CRT unit on VOCs emanated from the tail pipe of a direct injection compression ignition (DI-CI) engine facilitated with a turbocharger. In this paper, the research is extended to evaluate the potential of the unit to control the VOCs on account of secondary reactions which may promote the conversion/reduction of pollutant species in the presence of catalysts. Although a great deal of research has been reported in literature regarding the effects of CRT on regulated PM and gaseous emissions (Liu et al., 2011; Kittelson et al., 2006; Lanni at el., 2001), findings on unregulated pollutants are scanly (Shah et al., 2012). Particularly, the work on VOC-emissions from diesel engine retrofitted with CRT is in its infancy and needs to be addressed comprehensively.

\section{Materials and Methods}

Engine operating conditions and fuel used. In the present study, a direct injection compression ignition engine of $2.771 \mathrm{~L}$ capacity was run on a test bench employing an electrical dynamometer (Dynas ${ }_{3}$ HT350, Schenck) as shown in Fig. 1. The main features of the engine are as follows:

Category $=4$-cylinder, 4-stroke, common rail, high pressure, inline type engine,

Stroke and bore $=102 \mathrm{~mm}$ and $93 \mathrm{~mm}$, respectively, Compression ratio and valves $=18.2: 1$ and 2 valves per cylinder,

Maximum torque and power=270 N-m @1900 rpm and 85 kW@3600 rpm, respectively, Air intake system = turbocharged, inter-cooled.

The experiments were performed on steady state conditions following a Chinese 8-mode test protocol designated as ISO 8178 Type C1 (Shah et al., 2014; Shah et al., 2011; He et al., 2009). First four modes of the test consist of $100,75,50$, and $10 \%$ of full load at the speed 


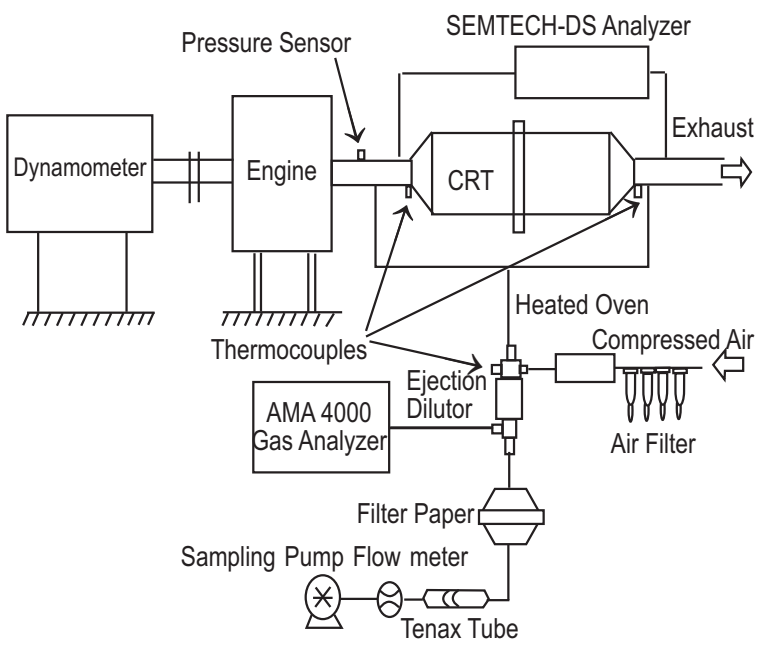

Fig. 1. Schematic diagram of test bed.

of $3600 \mathrm{r} / \mathrm{min}$, while the next three modes are devised at 100,75 , and $50 \%$ of full load at $1900 \mathrm{r} / \mathrm{min}$. The last or $8^{\text {th }}$ mode of the test is excogitated at no load (at a speed of $800 \mathrm{r} / \mathrm{min}$ ), and hence is known as an idle mode. The process of emission collection was performed twice during each mode of the cycle $(\mathrm{n}=2)$, and thus emissions are discussed here on the basis of their average values.

The engine was fuelled with locally available commercial diesel (Fuel Station in Beijing city). The properties and standards of the fuel are given in Table 1. The fuel and air flow rates were measured through PLU4000 (Pierburg Inc., Germany) and Sensyflow P (ABB Inc., Switzerland), respectively. The engine oil and coolant temperatures were measured using sensors Pt-100, while the thermocouple (k-series) was used to measure the exhaust temperature.

PLU4000 is a high performance fuel-consumption measuring device which is used as a flow meter for

Table 1. Properties and standards of fuel

\begin{tabular}{lll}
\hline \hline Properties & Diesel & Standard $^{\mathrm{a}}$ \\
\hline Sulphur content $(\mathrm{ppm})$ & 350 & $\mathrm{SH} / \mathrm{T}$ 0253-92 \\
Cetane number & 52 & $\mathrm{~GB} / \mathrm{T} 386-91$ \\
Oxygen content $(\%)$ & 0 & Element analysis \\
Viscosity $\left(\mathrm{mm}^{2} / \mathrm{s}\right)$ at $20^{\circ} \mathrm{C}$ & 4 & $\mathrm{~GB} / \mathrm{T} 265$ \\
Lower heating value $(\mathrm{MJ} / \mathrm{kg})$ & 42.8 & $\mathrm{~GB} / \mathrm{T} 384$ \\
Density $\left(\mathrm{kg} / \mathrm{m}^{3}\right)$ & 841 & $\mathrm{SH} / \mathrm{T} \mathrm{0604}$ \\
Carbon content $(\%)$ & 87 & $\mathrm{SH} / \mathrm{T} \mathrm{0656-98}$ \\
Hydrogen content $(\%)$ & 13 & $\mathrm{SH} / \mathrm{T} \mathrm{0656-98}$ \\
\hline \hline
\end{tabular}

${ }^{\mathrm{a} C h i n e s e}$ standard liquid fuels such as diesel, biodiesel, alcohol mixtures, etc. It is based on the well established fuel-measuring principle of the positive displacement counter in which change in pressure is equal to zero. It is controlled by the servo mechanism and is distinguished by its unique characteristic to achieve very short measuring times (less than $500 \mathrm{~ms}$ ), especially in case of low fuel consumptions. Thus, it facilitates to measure dynamic (transient) flows with high accuracy and a very good reproducibility. It can be used to measure the fuel consumption both on dynamometer based test bed as well as in-vehicle tests with equal ease. The detailed specifications of the device have already been discussed by Shah et al. (2009b).

Sensyflow P, on the other hand, is a tool used to measure the air on a test bench. It is employed for the direct mass-flow measurement of air without any additional pressure and temperature compensation requirements. It works on the principle of a hot-film anemometer, and thus consists of a measuring tube known as transducer, an evaluation unit and a measuring section.

CRT system and its features. After treatment, unit in the form of a CRT commercial package was retrofitted to above discussed engine. The specifications of the unit along with its construction and working principle are discussed in detail by Shah et al. (2012). However, some important parameters of the unit are given in Table 2 for more clarification. The substrate of trap on which catalyst is supported is made up of ceramic material held in the form of porous cordierite $(2 \mathrm{MgO}$. $2 \mathrm{Al}_{2} \mathrm{O}_{3} .5 \mathrm{SiO}_{2}$ ). The trap or filter chamber basically comprises wall-flow monoliths consisting of alternatively plugged channels of porous walls. The support material may affect the catalyst density and the diffusion of

Table 2. Specifications of the CRT unit

\begin{tabular}{ll}
\hline \hline Parameter & CRT \\
\hline Trap substrate & Cordierite \\
Trap Pt. content $\left(\mathrm{g} / \mathrm{ft}^{3}\right)$ & 35 \\
Trap cell density $\left(\mathrm{cells} / \mathrm{in}^{2}\right)$ & 200 \\
Structure & Porous, \\
& wall-flow monoliths \\
Diameter $\times$ Length $($ inch $\times$ inch $)$ & $8.5 \times 14$ \\
DOC substrate & Cordierite \\
DOC Pt. content $\left(\mathrm{g} / \mathrm{ft}^{3}\right)$ & 50 \\
DOC cell density $\left(\mathrm{cells} / \mathrm{in}^{2}\right)$ & 400 \\
Structure & honeycomb \\
Diameter $\times$ Length $(\mathrm{inch} \times$ inch $)$ & $8.5 \times 3.5$ \\
\hline \hline
\end{tabular}

$\mathrm{CRT}=$ continuously regenerating trap. 
reactants, and their subsequent products within the catalyst material. The DOC section of the unit, on the other hand, consists of a honeycomb substrate with its wash-coat comprising a thin layer of $\gamma$-alumina $\left(\mathrm{Al}_{2} \mathrm{O}_{3}\right)$ in which platinum $(\mathrm{Pt})$ catalyst is infused.

Methods of sampling, analysis and pollutant measurements. The engine exhaust was taken before and after the CRT unit in the Tenax TA ${ }^{\circledR}$ (Markes UK) tubes to get the upstream (baseline) and downstream measurements, respectively. Prior to trapping, the exhaust was first passed through an ejector diluter, and then through a filter for its purification. The dilution ratio of the diluter used to dilute the exhaust gas was about 8 . The diluter was calibrated through AMA4000 (Pierburg GmbH, Germany) and SEMTECH-DS (sensor, USA) analysers before sampling. For this purpose, two concentrations of carbon dioxide $\left(\mathrm{CO}_{2}\right)$ were passed through the analyzers before and after the diluter. Moreover, $\mathrm{NO}$ and $\mathrm{NO}_{2}$ were measured separately with the help of above discussed sensors as per sampling scheme shown in schematic diagram Fig. 1. For the suction of exhaust in Tenax tubes, a battery operated air pump of constant volume (Air Chek2000, SKC USA) was employed. Volume flow rate of the sample remained $0.3 \mathrm{~L} / \mathrm{min}$, while the sampling time was 10 min during each mode of the test. After completing the sampling task, tubes were sealed and kept at $-10{ }^{\circ} \mathrm{C}$ in a refrigerator for the subsequent analysis.

The trapped pollutants were extracted from the Tenax tubes through automatic thermal desorber (UNITY, Markes UK). For this purpose, sorbent tubes were eluted at $280^{\circ} \mathrm{C}$ for a period of $5 \mathrm{~min}$. The desorbed or removed material was concentrated in a cold trap cryogenically at $-10^{\circ} \mathrm{C}$. The material was then heated to $280{ }^{\circ} \mathrm{C}$ to volatilise it into the capillary column of gas chromatograph using a fused silica line. The VOC-components were finally analysed following the EPA standard (US EPA, 1999). In this way, following 8 components were identified and then quantified as:

Benzene, toluene, butyl acetate, ethyl benzene, $m$-xylene, styrene, $o$-xylene, and undecane.

VOCs identification was made through the US National Institute of Standards and Technology (NIST) using their mass spectral data. However, their quantification was achieved through external standard method making their linear standard curves. Thus, commercial standard liquids were taken in six different samples by making the use of a micro-sampler. The quantities of the purchased liquids were as follows: 1, 2, 4, 10, 20 and $40 \mu \mathrm{L}$. The standard gas supplied by the gas carrier was injected into the Tenax tube and then material was fed to $\mathrm{GC} / \mathrm{MS}$. The targeted pollutants were finally analysed in GC/MS using the regression method of their peak areas. Also, the relative standard deviation (RSD) of each compound was recorded. The quantitative ion for benzene, butyl acetate and undecane was 78, 43 and 57, respectively, while the same was 91 for rest of the components in each case. The correlation coefficients were in the range of 0.9873-0.9996, while RSD varied from 1.62-5.44 for the various compounds. The detailed thermal desorber-GC/MS programme has already been addressed by Shah et al. (2011) and Shah et al. (2009a).

\section{Results and Discussion}

Emissions of VOC-components. Figure 2 presents the VOCs emissions both upstream (baseline) and downstream of the CRT unit during various modes of the test. It is clear that VOCs are predominant at maximum load modes, decrease with the decreasing load, and then get increased again during 10\% load mode and idle mode at the speed of $3600 \mathrm{r} / \mathrm{min}$ and $1900 \mathrm{r} / \mathrm{min}$, respectively. In addition to this, VOCs are higher during the load modes of $3600 \mathrm{r} / \mathrm{min}$ speed relative to the corresponding modes at $1900 \mathrm{r} / \mathrm{min}$.

The higher VOCs at higher load modes as well as during maximum speed modes are attributed to the incomplete combustion caused by the richer mixture or lower relative air-to-fuel ratio $(\lambda)$. Rich mixture formation in the combustion chamber retards the fuel oxidation rates with the consequent volatile species originating from unburned fuel, oil fumes, water, etc. (Shah et al., 2011;

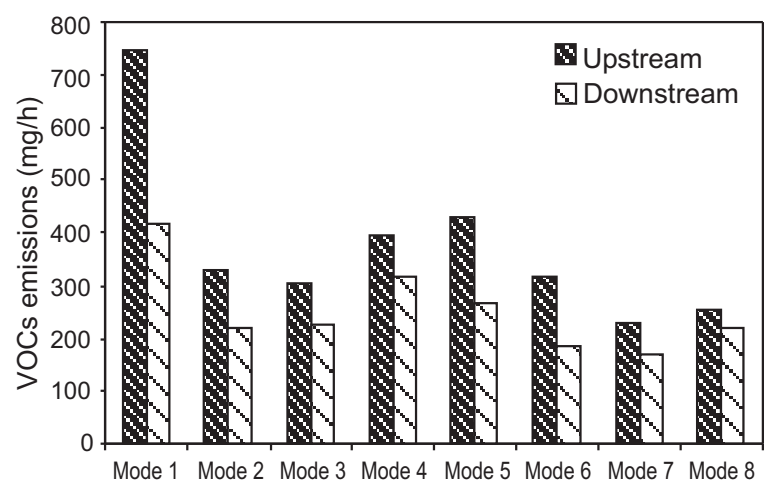

Fig. 2. Emissions of VOC-components upstream and downstream of CRT system. 
Shah et al., 2009a; Kittleson, 1998). Also, the elevated behaviours of VOCs at idle to $10 \%$ load modes may again be associated with incomplete combustion but this time owing to higher $\lambda$ values. The emission abatement trends of VOCs during 50-75\% load modes of both speeds of the test are indicative of an optimal load range during which more complete combustion of fuel takes place most likely due to the optimum engine operating parameters such as $\lambda$, combustion temperature, back pressure, etc. Such optimum parameters are more conducive for the decomposition of VOC-species.

Relative contributions of VOCs. Relative contribution (RC) is the contribution made by an individual component to the total pollutants under discussion. Figure 3(a) shows the RC of individual components of VOCs in upstream of the CRT unit during various modes of the test. Among the VOC-components, benzene and toluene are predominant species of baseline measurements with RC of $16-40.3 \%$ and $18-34.7 \%$, respectively. The next major contributors are ethyl benzene and undecane with RC of $10.6-16 \%$ and $8-19.5 \%$, respectively. $O$-xylene, $p$-xylene, styrene, and butyl acetate are the subsequent contributors to VOCs with same order of magnitude in the baseline or upstream measurements.

Figure 3(b) presents the RC of various VOC-species downstream of the CRT system. In this case toluene and ethyl benzene are dominant congeners of VOCs with RC of $21.4-38.2 \%$ and $9.4-30.8 \%$, respectively. However, benzene and undecane are the next major contributors to total VOCs with RC of $9-33.2 \%$ and $8-18.5 \%$, respectively. Butyl acetate once again remains the least contributor to VOC-components.

It is pertinent to note that benzene which remained dominant to toluene at full load modes of both cyclic speeds during the baseline measurements was greatly abated with CRT. However, baseline toluene which exhibited the highest RC to VOCs during all the cyclic modes except full load modes retained its predominant status even in downstream of the CRT unit. Moreover, ethyl benzene which was third major contributor among the baseline measurements came up as second largest contributor to VOCs with CRT system.

The reduction in $\mathrm{RC}$ made by benzene in general and during full load modes in particular may be attributed to the oxidation or conversion of benzene to other species in the presence of DOC. As benzene becomes highly unstable at higher temperatures during full load modes owing to its weaker C-H bonds (Shah et al., 2011), so (a)

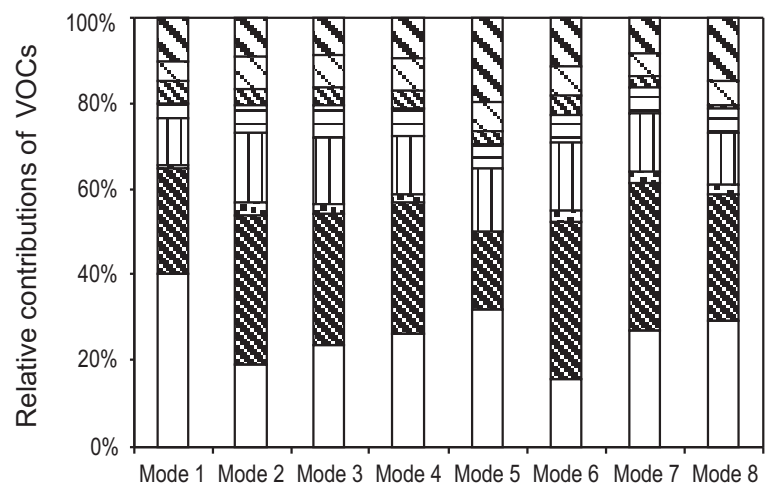

(b)

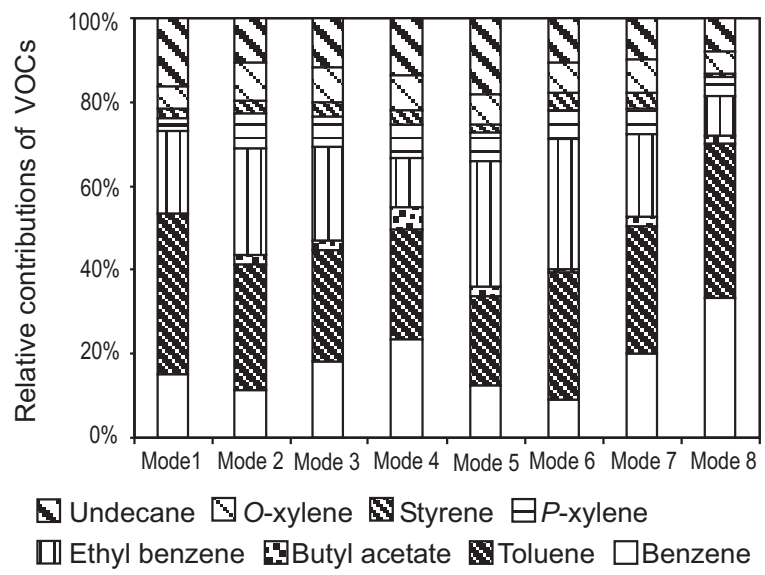

Fig. 3(a-b). Relative contribution of VOC-components (a) upstream and (b) downstream of CRT.

it might possibly be converted to other VOCs, semiVOCs and particulates not measured in this study.

Role of $\mathrm{NO}_{2} / \mathrm{NO}_{\mathrm{x}}$ ratio on the conversion of VOCs. The reduction rate of VOC-emissions with CRT unit is defined as follows:

$$
\mathrm{R}_{\mathrm{R}}=\frac{\left(\mathrm{U}_{\mathrm{VE}}-\mathrm{D}_{\mathrm{VE}}\right)}{\mathrm{U}_{\mathrm{VE}}} \times 100
$$

where:

$\mathrm{U}_{\mathrm{VE}}$ and $\mathrm{D}_{\mathrm{VE}}$ are upstream and downstream VOCemissions, respectively.

It is obvious from Fig. 4 that, an appreciable conversion ranging from $15.3-45 \%$ is achieved with CRT, and that there is a strong correlation between $\mathrm{R}_{\mathrm{R}}$ and $\mathrm{NO}_{2} / \mathrm{NO}_{\mathrm{x}}$ ratio. The VOCs reduction shows a strong dependence on these ratios during almost the entire cycle of the test. 
Generally, the $\mathrm{R}_{\mathrm{R}}$ trend is decreasing with the decreasing $\mathrm{NO}_{2} / \mathrm{NO}_{\mathrm{x}}$ ratio, however, it remains a bit higher at Mode 3 and Mode 6 relative to their preceding higher load modes (i.e. Mode 2 and Mode 5).

The higher $\mathrm{R}_{\mathrm{R}}$ of VOCs at elevated $\mathrm{NO}_{2} / \mathrm{NO}_{\mathrm{x}}$ ratio is due to the higher oxidation rates of VOCs along with some other gaseous emissions passing through the CRT retrofitted to the engine. It is well documented that $\mathrm{NO}_{2}$ is more potent oxidant of pollutants relative to oxygen $\left(\mathrm{O}_{2}\right)$ in the temperature range of $200-500{ }^{\circ} \mathrm{C}$ (Liu et al., 2012; Setiabudi et al., 2004). Some researchers are of the view that, $\mathrm{NO}_{2}$ varies only $5-15 \%$ in normal cases, however under specific condition when temperature reaches to $300-350{ }^{\circ} \mathrm{C}$ in the presence of Pt-catalyst it may reach up to $50 \%$ of total $\mathrm{NO}_{\mathrm{x}}$ emitted from the engine (Liu et al., 2012; Marques et al., 2004; Ehrburger et al., 2002).

The higher $R_{R}$ at Mode 3 and Mode 6, on the other hand, may be ascribed to engine operating parameters including $\lambda$ and back pressure which are deemed to be more dominant here as compared to $\mathrm{NO}_{2} / \mathrm{NO}_{\mathrm{x}}$ ratio. It is probable that both $\lambda$ and $P$ are optimal at these medium load modes, and thus VOCs get abated. But at minimum load modes, $\mathrm{R}_{\mathrm{R}}$ again drops down most likely owing to the formation of aluminum sulphate $\left(\mathrm{Al}_{2}\left(\mathrm{SO}_{4}\right)_{3}\right)$ in the presence of porous cordierite $\left(2 \mathrm{MgO} .2 \mathrm{Al}_{2} \mathrm{O}_{3} .5 \mathrm{SiO}_{2}\right)$ of CRT and the subsequent deactivation of alumina wash-coat. It is conjectured that higher sulphur content (350 ppm) in the fuel was first oxidised to sulphur dioxide $\left(\mathrm{SO}_{2}\right)$, then to sulphur trioxide $\left(\mathrm{SO}_{3}\right)$, and finally to $\left(\mathrm{Al}_{2}\left(\mathrm{SO}_{4}\right)_{3}\right)$. The conditions were more favourable for $\left(\mathrm{Al}_{2}\left(\mathrm{SO}_{4}\right)_{3}\right)$ to coagulate at such lower load levels, and thus to play an important role in the deactivation of catalyst. Consequently, the oxidizing power of catalyst was inhibited leading to the adverse performance of CRT during minimum load modes.

Effect of temperature on the conversion of benzene and ethyl benzene. Figure 5 presents the relation between the downstream temperature and the reduction of benzene and ethyl benzene separately. A positive correlation is found between temperature and $R_{R}$ of benzene during all the modes of test. The $\mathrm{R}_{\mathrm{R}}$ of benzene is maximal during full load modes and then decreases with the decreasing temperature. It is rightly so because conditions are conducive for the decomposition of benzene as well as some other pollutants and for their subsequent reduction rates at such higher temperatures. The $\mathrm{R}_{\mathrm{R}}$ of benzene is $67.7 \%$ at and $61 \%$ at full load

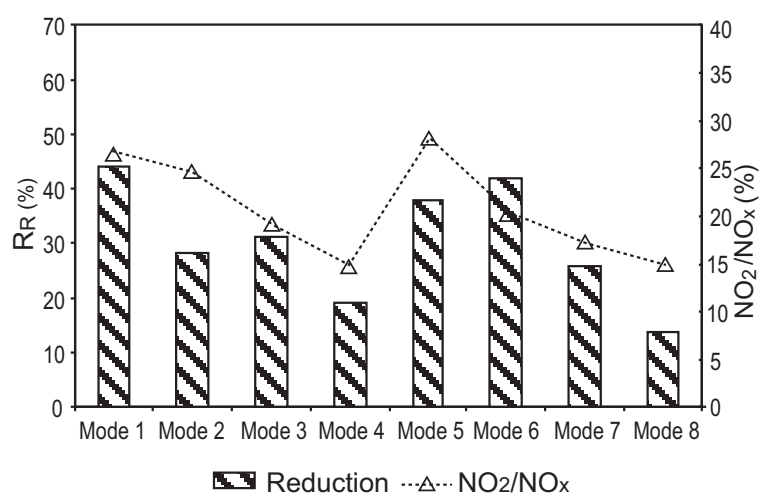

Fig. 4. Effect of $\mathrm{NO}_{2} / \mathrm{NO}_{\mathrm{x}}$ ratio on VOCs reduction.

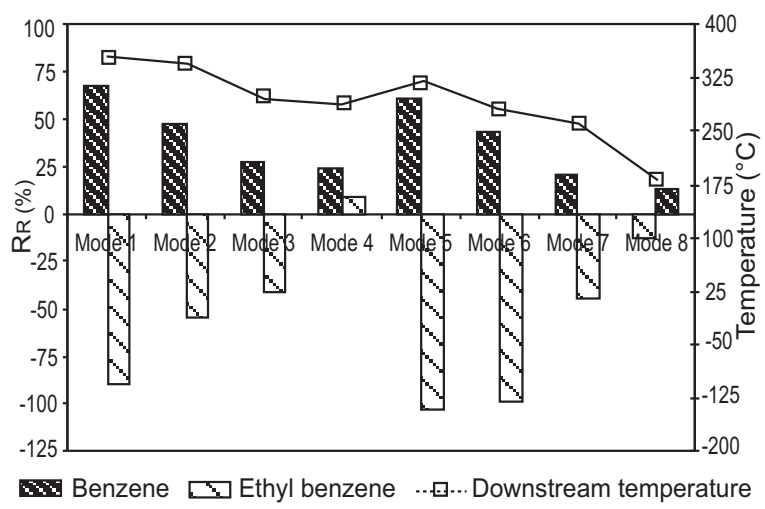

Fig. 5. Relationship between temperature and $R_{R}$ of benzene and ethyl benzene.

modes of both speeds during which cyclic temperature remains at its peak value. However, benzene shows negative $R_{R}$ value during idle mode of the test on account of insufficient temperature for its conversion.

The $R_{R}$ of ethyl-benzene, on the other hand, shows negative trends throughout the test except lower load modes (Mode 4 and Mode 8) during which ethyl benzene reflects some reduction rates of $8.5 \%$ and $13.7 \%$, respectively. The negative $R_{R}$ of ethyl benzene is more prominent at full load modes of both cyclic speeds as compared to other modes of the test. The maximum negative $R_{R}$ of ethyl benzene is up to $89 \%$ during Mode 1 and almost $100 \%$ at Mode 5 with CRT unit.

It is worthwhile to note that there is an anti-correlation between the reduction rates of benzene and ethyl benzene. The modes during which benzene exhibits maximum positive $R_{R}$, ethyl benzene reveals maximum negative $R_{R}$ during the same and vice versa. This trend 
of higher $\mathrm{R}_{\mathrm{R}}$ of benzene followed by deeper negative $R_{R}$ of ethyl benzene indicates that reactions involving such compounds in the presence of DOC and porous cordierite are different for the oxidation, and for their subsequent reduction.

\section{Conclusion}

A CRT commercial unit was studied to investigate its potential for the controlling of VOCs emitted from a turbocharged DI-CI engine. The engine was run on an AC electrical dynamometer under the directive of an 8-mode steady-state cycle. The diluted exhaust was trapped in Tenax $\mathrm{TA}^{\circledR}$ tubes, and then VOCs were analysed through GC/MS. The experimental results showed that VOCs were predominant during maximum load as well as minimum load modes on account of incomplete combustion engendered first by the lower value of $\lambda$ and then by the higher value of $\lambda$. Benzene and toluene were the most dominant components of baseline VOCs with maximum RC of 40.3 and $34.7 \%$, respectively. Ethyl benzene and undecane were the next major contributors to total baseline VOCs with maximum RC of 16 and $19.5 \%$, respectively. However, toluene and ethyl benzene were the major contributors in downstream of the CRT unit with maximum RC of 38.2 and $30.8 \%$, respectively. After them, benzene and undecane were the major contributors with RC of 33.2 and $18.5 \%$, respectively. Butyl acetate was the least contributor to total VOCs both in upstream and downstream of the CRT system. VOCs were substantially abated through the CRT unit and the maximum conversion/reduction rate was up to $45 \%$. A strong correlation was found between the $\mathrm{C}_{\mathrm{R}}$ of VOCs and $\mathrm{NO}_{2} / \mathrm{NO}_{\mathrm{x}}$ ratio, and the $\mathrm{R}_{\mathrm{R}}$ was decreased with the decrease in $\mathrm{NO}_{2} / \mathrm{NO}_{\mathrm{x}}$ ratio. Also, there was a positive correlation between downstream temperature and the $R_{R}$ of benzene, and the $R_{R}$ was reduced with the reduction in temperature. The modes during which the $R_{R}$ of benzene was higher, the negative $R_{R}$ of ethyl benzene was higher too due to the different reactions involved in these components.

\section{Acknowledgement}

Authors are highly indebted to Dr. Tan Jian-wei and Liu Zhi-hua for their help and guideline during the sample collection and in the analysis of pollutants through GC/MS. Thanks are also due to the lab staff for their support in conducting the tortuous series of experiments. Current work is financially supported by the National Natural Science Foundation of China (40805053).

\section{References}

Allansson, R., Blakeman, P.G., Cooper, B.J., Hess, H., Silcock, P.J., Walker, A.P. 2002. Optimising the low temperature performance and regeneration efficiency of the continuously regenerating diesel particulate filter (CR-DPF) system. Society of Automotive Engineering (SAE) Technical Paper Series, No.2002-01-0428.

Biswas, S., Verma, V., Schauer, J.J., Sioutas, C. 2009. Chemical speciation of PM emissions from heavyduty diesel vehicles equipped with diesel particulate filter (DPF) and selective catalytic reduction (SCR) retrofits. Atmospheric Environment, 43: 1917-1925.

Cooper, B.J., Thoss, J.E. 1989. Role of NO in diesel particulate emission control. Society of Automotive Engineering (SAE) Technical Paper Series, No. 890404.

Ehrburger, P.B., Brilhac, J.F., Drouillot, Y., Logie, V., Gilot, P. 2002. Reactivity of soot with nitrogen oxides in exhaust stream. Society of Automotive Engineering (SAE) Technical Paper Series, No. 2002-01-1683.

Haupt, D., Nord, K., Egeback, K., Ahlvic, P. 2004. Hydrocarbons and aldehydes from a diesel engine running on ethanol and equipped with EGR, catalyst and DPF. Society of Automotive Engineering (SAE) Technical Paper Series, No.2004-01-1882.

He, C., Ge, Y.S., Tan, J.W., You, K.W., Han, X.K., Wang, J.F., You, Q., Shah, A.N. 2009. Comparison of carbonyl compounds emissions from diesel engine fueled with biodiesel and diesel. Atmospheric Environment, 43: 3657-3661.

Jiang, L., Ge, Y.S., Shah, A.N., He, C., Liu, Z. 2010. Unregulated emissions from a diesel engine equipped with vanadium-based urea-SCR catalyst. Journal of Environmental Sciences, 22: 575-581.

Kittelson, D., Wattl, W., Johnson, J., Rowntree, C.J., Coodier, S.P., Payn, M.J., Preston, W.H., Warrens, C.P., Ortiz, M., Zink, U., Goersmann, C., Twigg, M.V., Walker, A.P. 2006. Driving down on-highway particulate emissions. Society of Automotive Engineering (SAE) Technical Paper Series, No. 200601-0916.

Kittleson, D.B. 1998. Engine and nanoparticles: A review. Journal of Aerosole Science, 29: 575-588.

Lanni, T., Chatterjee, S., Conway, R., Windawi, H., Rosenblatt, D., Bush, C., Lowell, D., Evana, J., McLiean, R. 2001. Performance and durability evaluation of continuously regenerating particulate 
filters on diesel power urban buses at NY City transit. Society of Automotive Engineering (SAE) Technical Paper Series, No.2001-01-0511.

Liu, Z.H., Ge, Y.S., Tan, J.W., He, C., Shah, A.N., Ding, Y., Yu, L., Zhao, W. 2012. Impacts of continuously regenerating trap and particle oxidation catalyst on the $\mathrm{NO}_{2}$ and particulate matter emissions emitted from diesel engine. Journal of Environmental Sciences, 24: 624-631.

Liu, Z.H., Shah, A.N., Ge, Y.S., Ding, Y., Tan, J.W., Jiang, L., Yu, L., Zhao, W., Wang, C., Zeng, T. 2011. Effects of continuously regenerating diesel particulate filters on regulated emissions and number-size distribution of particles emitted from a diesel engine. Journal of Environmental Sciences, 23: 798-807.

Liu, Z.G., Berg, D.R., Vasys, V.N., Dettmann, M.E., Zielinska, B., Schauer, J.J. 2010. Analysis of C1, $\mathrm{C} 2$, and $\mathrm{C} 10$ through $\mathrm{C} 33$ particlephase and semivolatile organic compound emissions from heavyduty diesel engines. Atmospheric Environment, 44: 1108-1115.

Marques, R., Darcy, P., Da Costa, P., Mellottee, H., Trichard, J.M., Djega-Marriadassou, G. 2004. Kinetics and mechanism of steady-state catalytic $\mathrm{NO}+\mathrm{O}_{2}$ reactions on $\mathrm{Pt} / \mathrm{SiO}_{2}$ and $\mathrm{Pt} / \mathrm{CeZrO}$. Journal of Molecular Catalysis A: Chemical, 221: 127-136.

Setiabudi, A., Makkee, M., Moulijn, J.A. 2004. The role of $\mathrm{NO}_{2}$ and $\mathrm{O}_{2}$ in the accelerated combustion of soot in diesel exhaust gases. Applied Catalysis B: Environmental, 50: 185-194.

Shah, A.N., Yunshan, G., Shah, F.H., Mughal, H.U., Rahman, Z.U., Naveed, A. 2014. Effect of biodiesel on particulate numbers and composition emitted from turbocharged diesel engine. International Journal of Science and Technology, 11: 385-394.

Shah, A.N., Ge, Y.S., Tan, J.W., Liu, Z.H., He, C., Zeng, T. 2012. Characterization of polycyclic aromatic hydrocarbon emissions from diesel engine retrofitted with selective catalytic reduction and continuously regenerating trap. Journal of Environmental Sciences,
24: $1449-1456$

Shah, A.N., Ge, Y., Jiang, L. 2011. Impact of a ureaselective catalytic reduction system on volatile organic compound emissions from a diesel engine. The Arabian Journal for Science and Engineering, 36: 891-901.

Shah, A.N., Ge, Y.S., Tan, J.W., Liu, Z.H. 2009a. Experimental investigation of VOCs emitted from a DI-CI engine fuelled with biodiesel, diesel and biodiesel-diesel blend. Pakistan Journal of Scientific and Industrial Research, 52: 158-166.

Shah, A.N., Ge, Y.S., Tan, J.W., He, C. 2009b. Effects of biodiesel from soybean oil on the exhaust emissions of a turbocharged diesel engine. Pakistan Journal of Scientific and Industrial Research, 52: 217-227.

Tang, S., Frank, B.P., Lanni, T., Rideeout, G., Meyer, N., Beregszaszy, C. 2007. Unregulated emissions from a heavy duty diesel engine with various fuels and emission control systems. Environmental Science and Technology, 41: 5037-5043.

Tang, S., Graham, L., Shen, L., Zhou, X., Lanni, T. 2004. Simultaneous determination of carbonyls and $\mathrm{NO}_{2}$ in exhausts of heavy-duty diesel trucks and transit buses by HPLC following 2,4-dinitrophenylhydrazine cartridge collection. Environmental Science and Technology, 38: 5968-5976.

Walker, A.P., Allansson, R., Blakeman, P.G., Lavenius, M., Erkfeldt, S., Landalv, H., Landalv, H., Ball, B., Harrod, P., Manning, D., Bernegger, L. 2003. The development and performance of the compact SCR-trap system: A 4-way diesel emission control system. SAE Technical Paper Series, No.2003-010778.

US EPA, 1999. Determination of Volatile Organic Compounds in Ambient Air Using Active Sampling Onto Sorbent Tubes. Compendium Method TO-17, United States Environmental Protection Agency Washington, EPA/625/R-96/010b, pp. 1-53.

US EPA, 1990. Cancer Risk from Outdoor Exposure to Air Toxics. United States Environmental Protection Agency, Washington, vol. 1, EPA 450/1-90-004a. 